\title{
Le don Marc Bouloiseau à la bibliothèque de l'IRED (Université de Rouen)
}

Guy Lemarchand

\section{OpenEdition}

1 Journals

Édition électronique

URL : https://journals.openedition.org/ahrf/1839

DOI : 10.4000/ahrf.1839

ISSN : 1952-403X

Éditeur :

Armand Colin, Société des études robespierristes

Édition imprimée

Date de publication : 1 décembre 2000

Pagination : 172-173

ISSN : 0003-4436

Référence électronique

Guy Lemarchand, « Le don Marc Bouloiseau à la bibliothèque de l'IRED (Université de Rouen) »,

Annales historiques de la Révolution française [En ligne], 322 I octobre-décembre 2000, mis en ligne le 22 mars 2006, consulté le 24 avril 2022. URL : http://journals.openedition.org/ahrf/1839 ; DOI : https:// doi.org/10.4000/ahrf.1839

Ce document a été généré automatiquement le 24 avril 2022.

Tous droits réservés 


\title{
Le don Marc Bouloiseau à la bibliothèque de l'IRED (Université de Rouen)
}

\author{
Guy Lemarchand
}

1 Sachant que notre Centre de Recherche d'Histoire Comparée de la Transition consacrait une bonne partie de son activité à la Révolution et l'Empire, notamment avec C.Mazauric et Ch. Le Bozec, M. Bouloiseau eut en 1994 l'idée de donner une partie de sa bibliothèque au service de documentation qui était rattaché à notre groupe, ce dont encore aujourd'hui on ne saurait trop rendre hommage à sa mémoire. Notre collègue P.Dupuy assura le transport des précieuses brochures, revues et livres, de Saumur à Mont-SaintAignan, et d'un seul coup nos collections de travaux furent enrichies d'ouvrages dont beaucoup aujourd'hui sont difficiles à se procurer et se trouvent souvent dispersés entre de nombreux dépôts. Il s'agit d'un ensemble de près de 400 titres publiés pour la plupart entre 1955 et 1980, quelques uns remontant à l'entre-deux-guerres, et dont la majorité est constituée de tirés-à-part de revues d'histoire et d'actes de colloques et de congrès. Ils portent presque tous sur la période moderne, surtout le xviIIe siècle, la Révolution et l'Empire. Leur liste permet de mesurer l'ampleur de la curiosité scientifique de M. Bouloiseau, son travail de découvreur d'archives et la multiplicité des relations qu'il entretenait avec les historiens français et étrangers.

2 Un premier ensemble est constitué d'inventaires de fonds de documents divers des Archives Nationales, telle que la série du Comité de Sûreté générale ou la Marine B9, et pour les Archives départementales les séries $C$ et $D$ de Seine-Inférieure. Les publications de sources figurent en bonne place Recueil des actes du Comité de Salut public, Archives parlementaires, etc. En ce qui concerne les travaux, il y a d'abord cette masse d'articles et communications de colloques, particulièrement d'auteurs ayant travaillé sur la Normandie tels A. Dubuc, Ch. Leroy, R. Rouault de la Vigne ou J. Vidalenc, sur la Picardie avec R. Legrand ou sur Lyon et le Nord comme L. Trenard, de P. Leuilliot sur l'Alsace ainsi que sur l'organisation de la recherche en histoire, ou sur les Antilles avec G.Debien. On y trouve également des contributions peu présentes dans nos 
bibliothèques d'historiens étrangers, M. Hutt de Londres, B. Lesnodorski de Varsovie, V.Daline de Moscou, A. Dutu de Bucarest, etc. Le plus volumineux est sans doute constitué par les collections de revues sur plusieurs années, Bulletin de la Société d'Émulation de Seine-Maritime, Annales de Normandie ... et les actes de congrès, colloques $\mathrm{du}$ CNRS comme celui sur l'Abolition de la féodalité en Occident, Congrès Nationaux des Sociétés Savantes ou Congrès internationaux des Sciences Historiques.

3 Un tel don a évidemment été un apport important pour la bibliothèque de notre groupe de recherches il a permis à ses membres d'avoir sous la main une documentation de consultation fréquente, notamment pour des spécialistes de la période révolutionnaire. À l'énoncé des diverses catégories qui composent ce fonds, on voit également combien M. Bouloiseau était attentif à la recherche locale, ce qui n'étonnera pas les lecteurs de sa publication modèle des cahiers de doléances du bailliage de Rouen, mais aussi ouvert à la production historique hors de l'hexagone et aux grands problèmes d'interprétation qu'elle pose. 